\title{
Conf-9405322 -
} Monsoon Simulations

\author{
K.R Sperber \\ Program for Climate Model Diagnosis and Intercomparison \\ Lawrence Livermore National Laboratory \\ P.O. Box 808, L-264 \\ Livermore, California 94551 USA \\ and \\ T.N. Palmer \\ European Centre for Medium-Range Weather Forecasts \\ Shinfield Park \\ Reading, Berkshire RG2 9AX \\ United Kingdom \\ This paper was prepared for submittal to \\ Proceedings of the International Conference on \\ Monsoon Variability and Prediction \\ Trieste, Italy \\ 9-13 May 1994
}

June 1994

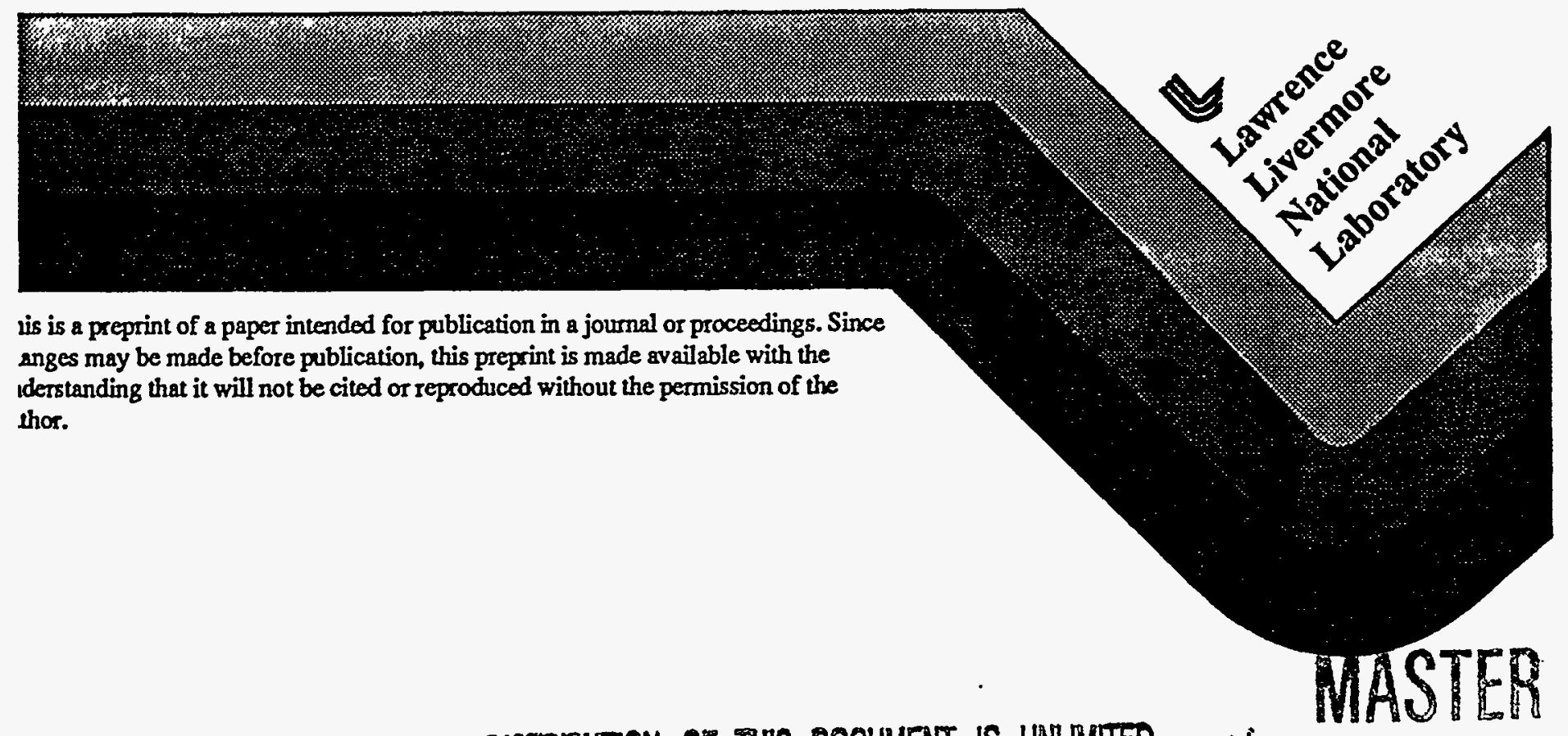




\section{DISCLAIMER}

This report was prepared as an account of work sponsored by an agency of the United States Government. Neither the United States Government nor any agency thereof, nor any of their employees, make any warranty, express or implied, or assumes any legal liability or responsibility for the accuracy, completeness, or usefulness of any information, apparatus, product, or process disclosed, or represents that its use would not infringe privately owned rights. Reference herein to any specific commercial product, process, or service by trade name, trademark, manufacturer, or otherwise does not necessarily constitute or imply its endorsement, recommendation, or favoring by the United States Government or any agency thereof. The views and opinions of authors expressed herein do not necessarily state or reflect those of the United States Government or any agency thereof. 


\section{DISCLAIMER}

Portions of this document may be illegible in electronic image products. Images are produced from the best available original document. 


\title{
ATMOSPHERIC MODEL INTERCOMPARISON PROJECT: MONSOON SIMULATIONS
}

\author{
K. R. Sperber ${ }^{1}$ and T. N. Palmer ${ }^{2}$ \\ ${ }^{1}$ Program for Climate Model Diagnosis and Intercomparison \\ Lawrence Livermore National Laboratory \\ P. O. Box 808, L-264 \\ Livermore, CA 94551 \\ ${ }^{2}$ European Centre for Medium-Range Weather Forecasts \\ Shinfield Park, Reading, Berkshire RG2 9AX \\ United Kingdom
}

\section{INTRODUCTION}

The simulation of monsoons, in particular the Indian summer monsoon, has proven to be a critical test of a general circulation models ability to simulate tropical climate and variability (WMO 1992, 1993). The Monsoon Numerical Experimentation Group has begun to address questions regarding the predictability of monsoon extremes, in particular conditions associated with El Nino and La Nina conditions that tend to be associated with drought and flood conditions over the Indian subcontinent (Ropelewski and Halpert 1987, 1989), through a series of seasonal integrations using analyzed initial conditions from successive days in 1987 and 1988. In this paper we present an analysis of simulations associated with the Atmospheric Model Intercomparison Project (AMIP), a coordinated effort to simulate the 1979-88 decade using standardized boundary conditions with approximately 30 atmospheric general circulation models (Gates 1992). The 13 models analyzed to date are listed in Table 1. Using monthly mean data from these simulations we have calculated indices of precipitation and wind shear in an effort to access the performance of the models over the course of the AMIP decade.

\section{MONSOON EXTREMES}

1987 and 1988 were El Nino and La Nina years respectively. Throughout the central and eastern tropical Pacific Ocean, the 1988 SSTs were colder than those in 1987 by upwards of $2^{\circ} \mathrm{C}$, with maximum differences reaching $4.5^{\circ} \mathrm{C}$ (WMO 1992). Examination of the observed 1988-1987 differences of June/July/August (JJA) averaged precipitation and lowlevel flow at $850 \mathrm{hPa}$ indicate that there were several features that contributed to the enhanced precipitation over the Indian subcontinent, the Arabian Sea and the tropical Indian Ocean (Figs.1a and 1c). The enhancement of the Somali jet in conjunction with the presence of low-level equatorial easterlies were associated with convergence and enhanced precipitation over the southern portion of the subcontinent and over the ocean, while over the northwestern portion of the subcontinent stronger westerly flow and suppressed dry-air advection contributed to the increased precipitation. Additionally, southeasterly anomalies over the Bay of Bengal strongly suggest that interannual changes in the behavior of the monsoon trough affected the distribution of precipitation over the northeastern portion of the subcontinent. Due to the paucity of observations, particularly over the Indian Ocean, the verification fields are subject to uncertainty. Table 1 subjectively indicates the ability of the models 

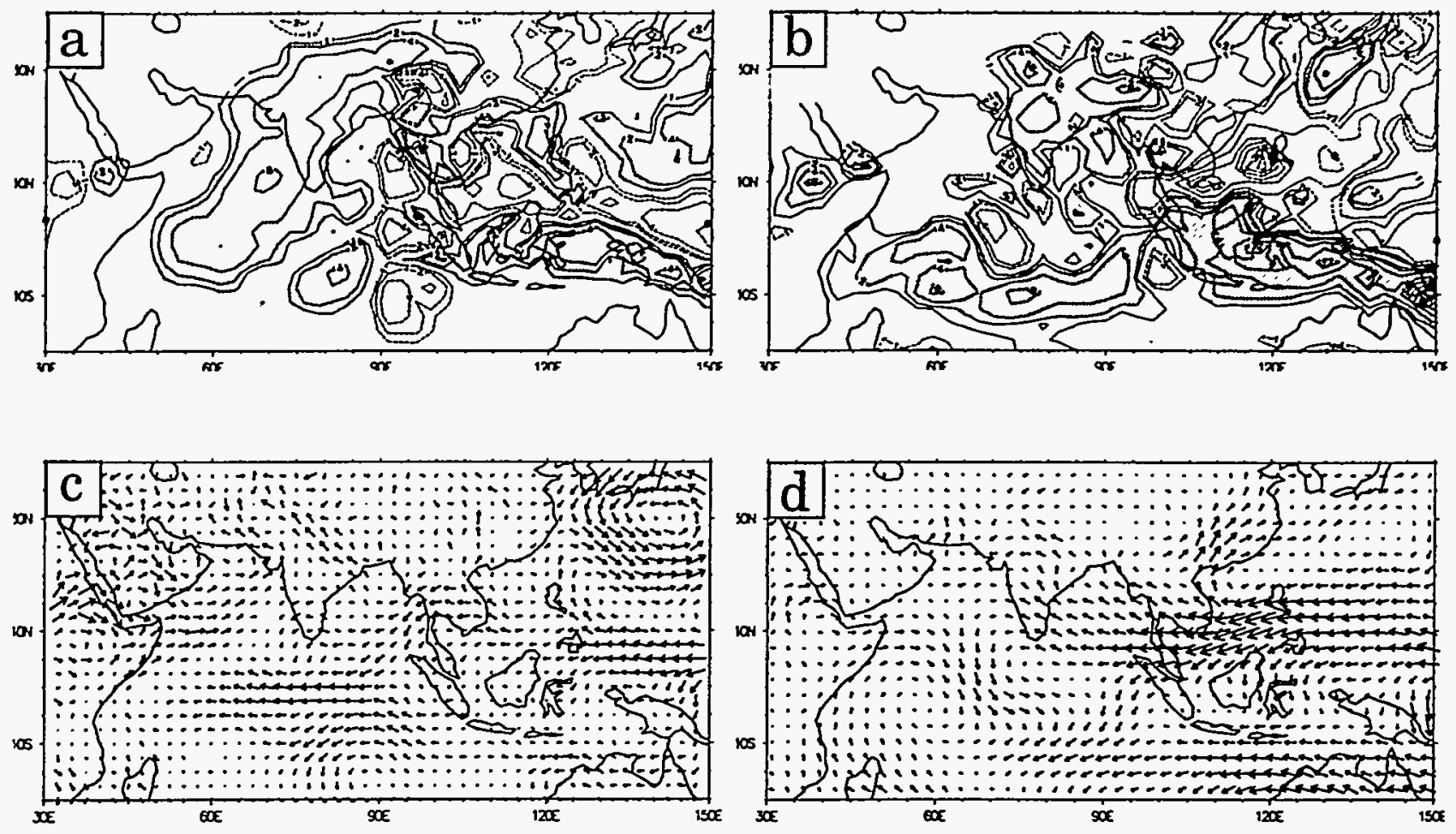

Figure 1. 1988-1987 differences of June/July/August averaged precipitation (mm/day) a) GPCP satellite derived precipitation, b) ECMWF AMIP simulation; and 850hPa winds c) ECMWF initializations d) ECMWF AMIP simulation. Precipitation anomalies greater than or equal $1 \mathrm{~mm} /$ day are shaded. Positive (negative) contours are solid (dashed). Contours are given for anomalies $+/-1,2,4,8,12 \ldots \mathrm{mm} /$ day.

the subcontinent or the ocean through enhanced surface evaporation. To varying extents southeasterly anomalies over the Bay of Bengal and the continent were simulated. Those models that have been successful in qualitatively simulating enhanced precipitation exhibit difficulty in simulating the spatial characteristics of the signal with fidelity. As an example, the 1988-1987 JJA differences of precipitation and 850hPa winds from the ECMWF (Cycle 36) AMIP, simulation are given in Figs. $1 \mathrm{~b}$ and $1 \mathrm{~d}$. The enhanced precipitation over the Indian subcontinent in this simulation arises as a consequence of southeasterly anomalies over the Bay of Bengal that extend over the Indian subcontinent. These anomalies are indicative of monsoon trough displacements and suppressed dry-air advection in 1988 relative to 1987.

In an effort to ascertain the robustness of the ECMWF models response to the prescribed sea-surface temperatures, four additional AMIP sensitivity simulations have been examined. These 10-year runs only differed in the prescription of the initial conditions. Examination of an all-India rainfall index (land points only) from these runs indicated that in each case the Indian subcontinent was wetter during the summer of 1988 than 1987, and that the low-level flow anomalies were qualitatively similar. With respect to each year, the rainfall departures were of similar magnitude during 1987 while those during 1988 exhibited a larger spread indicating that this models response to the El Nino conditions of 1987 was more coherent than its response to the La Nina conditions of 1988.

Examination of the 10-year JJA averaged precipitation and low-level flow climatologies from the ensemble of AMIP integrations (not shown) suggest that a weak Somali jet is associated with an underestimate of precipitation over India. Hence, while it is necessary to sim- 

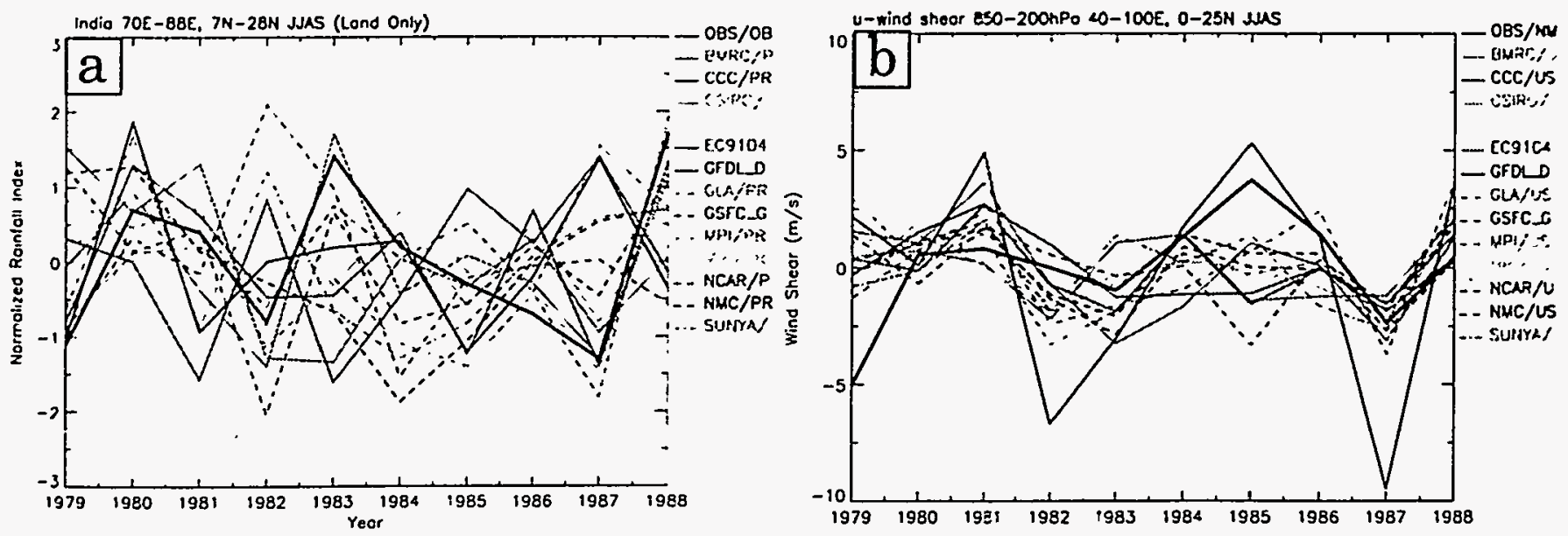

Figure 2. June/July/August/September averaged simulated and observed a) all-India rainfall indices (land only). For each model the index is normalized by removing the mean and dividing by the standard deviation. The observed index (thick black line) is based on data from Parthasarathy et al. (1992). b) u-wind shear indices $(850-200 \mathrm{hPa})$ over the summer monsoon region. The observed index is based upon NMC CDDB analyses.

ulate the large-scale flow in order to obtain a good monsoon precipitation distribution, there are other regional scale phenomena, such as the behavior of the trough in the Bay of Bengal and the dry-air advection from the northwest, that play important roles as mechanisms in moderating monsoon precipitation on seasonal and interannual time scales. Examination of these various regional attributes in the 10-year climatologies may aid in delineating those models that may have more success at properly simulating the observed interannual variations. However, this is a subjective procedure. Rather, an objective procedure for classifying a models performance will be discussed in the next section.

\section{VARIATIONS DURING THE PERIOD 1979-88}

The ability of the models to simulate Indian monsoon precipitation variations over the course of the AMIP decade is presented in Fig. 2a. This is a June/July/August/September averaged area-weighted all-India rainfall index and the verification data (heavy black line) is taken from Parthasarathy et al. (1992). For each model the rainfall index has been normalized by removing the mean and dividing by the standard deviation. Presented in this manner, the index indicates little or no coherence among the simulations in representing the observed interannual variations of Indian monsoon rainfall, even during 1987 and 1988 when the large SST anomalies associated with El Nino and La Nina provided a substantial perturbation to the tropical flow. That the models had more success in representing changes in the large-scale flow, at least in showing some coherence in their dynamical response to the SSTs, can be seen in Fig. 2b, a u-wind shear index akin to that described by Webster and Yang (1992). From 1983 onwards the behavior of the NMC and ECMWF (not shown) analyzed wind shear indices are comparable. Acknowledging the shortcomings of dealing with analyses due to changing models and initialization/analyses procedures, we see that the dynamical index is a much less stringent means of verifying a models ability to simulate interannual monsoon fluctuations. The models show marked agreement in their behavior during 1986-88, showing increased shear (stronger Somali jet and enhanced upper level easterly flow) in 1988 relative to 1987 . They also exhibit coherent behavior during the early 1980 's. 

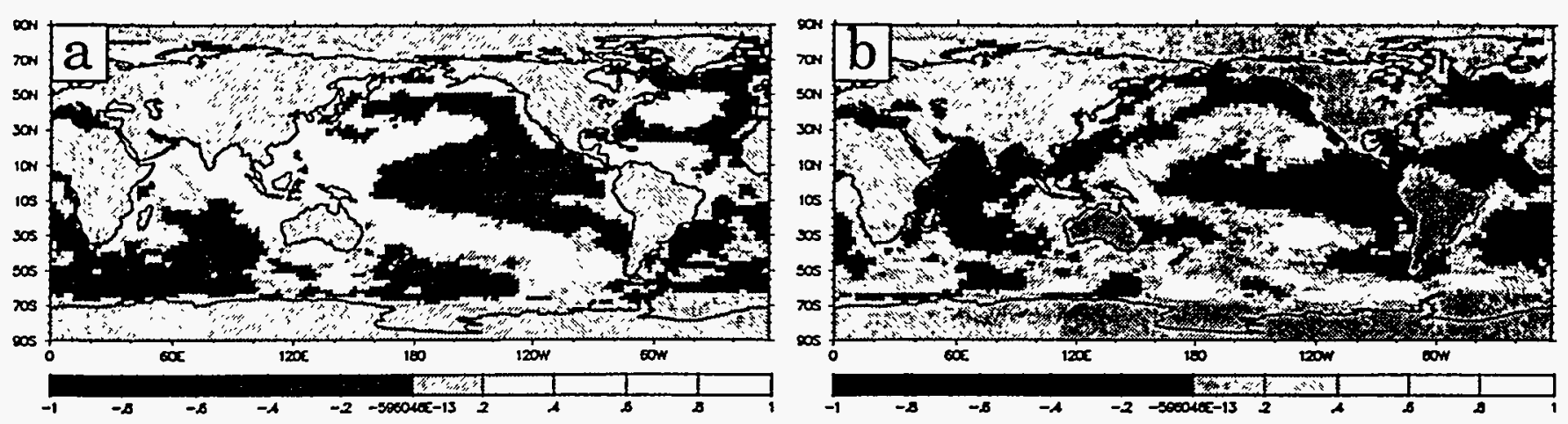

Figure 3. June/July/August averaged SST correlated with June/July/August/September averaged a) all-India rainfall index (Parthasarathy et al. 1992) b) u-wind shear (NMC CDDB analyses) for the period 1979-1988. Regions of positive (negative) correlation are lightly (darkly) shaded.

A question of interest is: How can we objectively classify the performance of the models in an effort to find some underlying order in their ability to represent the precipitation variations over the Indian subcontinent seen in Fig.2a? A useful method for discriminating model performance is through the use of teleconnection studies. Given that all of the simulations have the same SST data set in common (although transformed to the horizontal grid specific to a given model) we can correlate a models all-India rainfall index with the SST as a quantitative measure of a models ability to correctly respond to the imposed surface forcing. The link between the monsoon wind shear indices and the SST can be explored in the same fashion. Verification data against which we may compare the simulated teleconnection patterns are presented in Fig. 3. These are contemporaneous correlations of the observed all-India rainfall index (Parthasarathy et al. 1992), and NMC analyzed u-wind shear, as given in Fig. 2 , with the SST for the period 1979-1988. Given the few degrees of freedom, eight, we have chosen to preserve the spatial information of the correlations, even for those that fall below the $95 \%$ confidence level $(|r|<0.63)$. Both the all-India rainfall and $u$-wind shear indices show a pronounced ENSO teleconnection relationship with the SST. Enhanced (decreased) precipitation over India and enhanced (decreased) $u$-wind shear over the summer monsoon region occur when the SST in the tropical Pacific Ocean is below (above) normal. In the last column of Table 1 we indicate with a " + " sign the models that have successfully represented the observed rainfall/SST ENSO teleconnection pattern given in Fig. 3a. Eight of the thirteen models have shown an ability to at least qualitatively simulate this relationship, while six of thirteen models actually produced an inverse relationship to that observed, as indicated by the " $m$ " sign in the last column of Table 1 . That is, these latter models responded incorrectly to the SST forcing, having a positive correlation between the all-India precipitation and SST in the tropical central and eastern Pacific. When this objective measure of a models simulation is taken into account, we find that only those models that successfully represented the proper teleconnection pattern given in Fig. 3a were able to simulate the precipitation anomalies over the subcontinent in 1988 relative to 1987 (models shaded in Table 1). In Fig.4 we show the 1979-1988 all-India rainfall indices from these models. The indices from this reduced set show more coherency in their interannual variations relative to the ensemble of simulations presented in Fig. 2a, particularly during the later portion of the AMIP decade. Although 1982 and 1983 were also dry and wet years, analogous to 1987 and 1988, the "universal" coherency exhibited by this reduced set in the rainfall anomaly tendency from 1987 to 1988 is not found in 1982 and 1983 . This is likely to be related to differences in the 


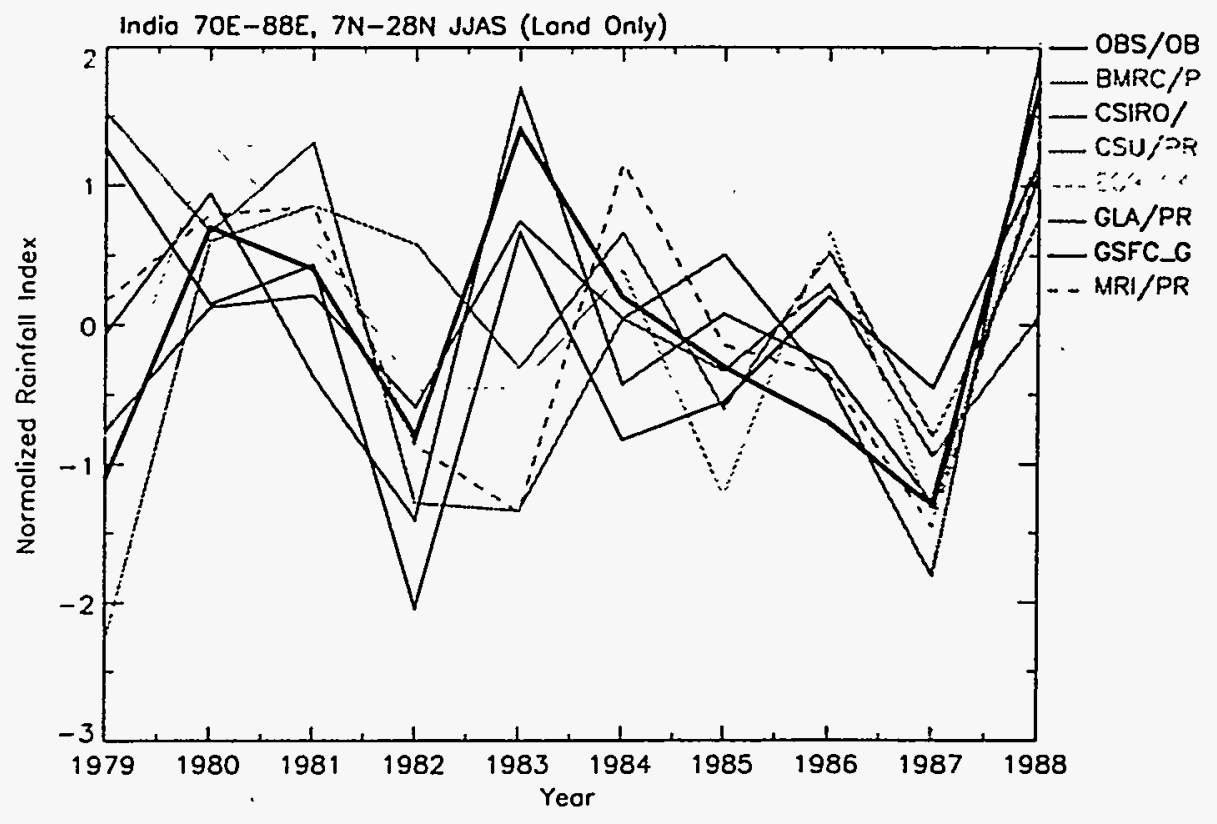

Figure 4. June/July/August/September averaged simulated and observed all-India rainfall indices (land only) for those models (shaded in Table 1) that have successfully represented the rainfall/SST teleconnection given in Fig. 3a.

magnitude of the anomalous surface forcing in 1982/1983 versus 1987/1988, as seen in Fig. 5. In the 1983-1982 SST difference, Fig. 5a, the cold anomalies in the tropical Pacific Ocean fail to extend to the South American coast and they never exceed $2^{\circ} \mathrm{C}$, while, as noted earlier, the 1988-1987 cold anomalies, Fig. $5 \mathrm{~b}$, exceeded $2^{\circ} \mathrm{C}$ and reached a maximum of nearly $4.5^{\circ} \mathrm{C}$. Additionally, the clear ENSO pattern seen in the 1988-1987 anomalies is absent in the 1983-1982 anomalies, with less coherent behavior in the Pacific Ocean and warming in excess of $2^{\circ} \mathrm{C}$ in the eastern tropical Pacific and maxima $>3^{\circ} \mathrm{C}$ near the west coast of South America.

All of the models were qualitatively successful at simulating the $\mathrm{u}$-wind shear/SST teleconnection pattern shown in Fig. 3b. As seen in Fig. 2b, the models exhibit commonality in the early 1980's and particularly during the later portion of the AMIP decade during the transition into and between the El Nino and La Nina conditions.

\section{DISCUSSION AND CONCLUSIONS}

In an effort to evaluate the ability of atmospheric general circulation models to simulate observed monsoon variations we have analyzed many of the models participating in the Atmospheric Model Intercomparison Project, a coordinated experiment to simulate the period 1979-88. We have found that the ability of a model to correctly simulate interannual variations is related to its ability to correctly portray a realistic climatology and to respond to remote SST forcing.

Examination of the 10-year mean climatologies from the simulations indicates that regional scale characteristics of the low-level flow can have dramatic consequences on the distribution of precipitation over the monsoon region. For instance, many models simulated a Somali jet that compared well with observations. This is generally assumed to be related to a models ability to properly represent the precipitation along west coast of India. While we 

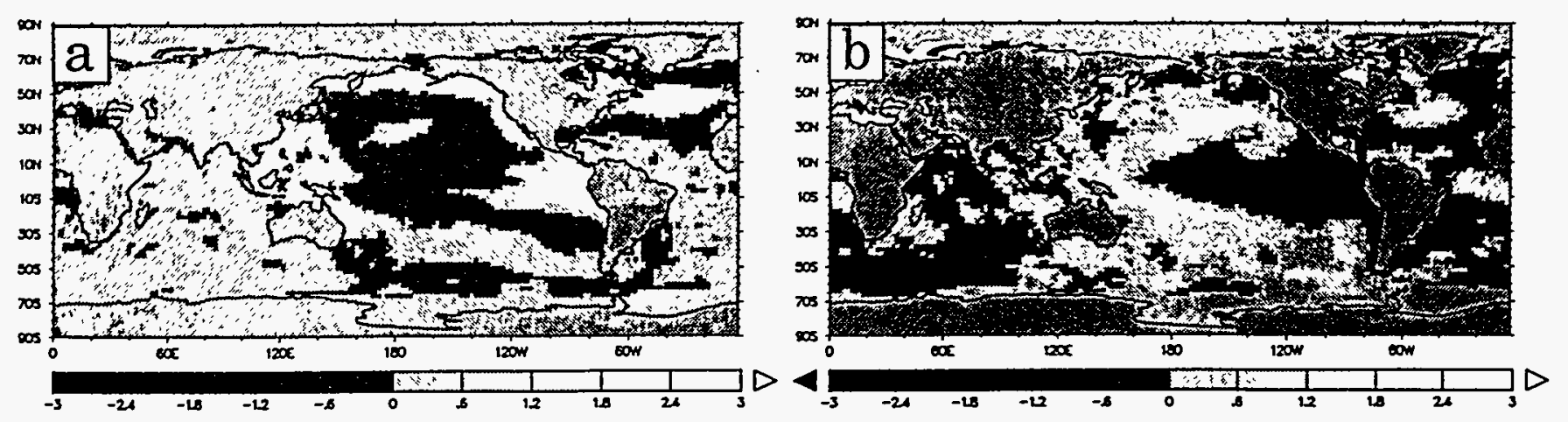

Figure 5. June/July/August averaged differences in sea-surface temperature $\left({ }^{\circ} \mathrm{C}\right)$ a) 1983-1982 b) 1988-1987.

have generally found this to be the case in these simulations, the nature of the low-level flow over Pakistan, Afghanistan and the Saudi peninsula also play a crucial role. When flow from these regions is excessive, dry hot air is advected into the monsoon region, and this precludes the moisture converge necessary to produce the copious amounts of precipitation associated with the monsoon. This is but one example of the many controlling influences that govern the monsoon which must be modelled adequately if GCMs are to be used as a tool for monsoon predictability.

With regard to the influence of the remote SST forcing, nearly half of the models evaluated exhibited fundamental difficulties by their failure to even realize the correct phase of the observed all-India rainfall/SST teleconnection. Using such teleconnections provides an objective means of stratifying model performance. We find that the link between Indian monsoon rainfall and SST is strongest under ENSO conditions, particularly when substantial anomalies in the tropical Pacific Ocean persist during June-September. At other times little or no consensus among the simulations exists with regard to Indian monsoon rainfall, even in the initial condition sensitivity simulations performed with the ECMWF model. The use of an all-India rainfall index as a means of model verification has proven to be a stringent test of a models ability to simulate interannual variations. However, the models tend to respond in a similar fashion on the large-scale given the similarity of their dynamical response to the SST, as indicated by the monsoon wind shear index and it relationship to the SST.

Under the extreme conditions associated with the $1987 \mathrm{El} \mathrm{Nino}$ and $1988 \mathrm{La}$ Nina drought and flood conditions over India, more than half of the models were able to qualitatively produce enhanced precipitation over the subcontinent in 1988 relative to 1987 . Generally, these models were only able to simulate a subset of the low-level flow characteristics deemed influential in producing the anomalous precipitation. Alternatively, none of the models were able to properly capture the enhanced precipitation that was observed to extend from the southwest of the subcontinent to the Arabian Sea and tropical Indian Ocean. This arose since the models were not able to produce the low-level equatorial easterlies, that in conjunction with an enhanced Somali jet were associated with anomalous convergence in this region.

We have also analyzed five 10-year AMIP simulations performed with the ECMWF model. These simulations differed only in the prescription of the initial conditions. These integrations are useful for estimating the robustness of the forced response. The Indian monsoon rainfall and flow climatologies were robust. This is quite interesting given the year to year differences among the simulations as evidenced by the all-India rainfall indices (not 
shown). The 1988-1987 differences showed similar structure with the precipitation enhancement over the subcontinent being associated with reduced dry air advection from the northwest and southeasterly anomalies over the Bay of Bengal, the latter being suggestive of monsoon trough perturbations. While all were wetter over the subcontinent in 1988 relative to 1987 , four out of five realizations produced wetter conditions relative to the 1979-1988 climatology. This indicates that this particular model can qualitatively represent relative impacts over this region but not absolute responses to the remote forcing.

In the future we will analyze the monsoon simulations of the remainder of the AMIP models. We will also pursue lagged teleconnection studies of the various indices with surface variables, such as snow cover and soil moisture, in an effort to ascertain the hierarchy of controlling factors that make it inherently difficult to simulate, hindcast and predict monsoon variability.

Acknowledgment. This work was performed under the auspices of the Department of Energy Environmental Sciences Division at the Lawrence Livermore National Laboratory under contract W-7405-ENG-48.

\section{REFERENCES}

Gates, W. L., 1992: The atmospheric model intercomparison project. Bull. Amer. Meteorol. Soc., 73, 1962-1970.

Parthasarathy, B., Kumar, K. R. and Kothawale, D. R., 1992: Indian summer monsoon rainfall indices: 1871-1990. Meteorol. Mag. 121, 174-186.

Ropelewski, C. F. and Halpert, M. S., 1987: Global and regional scale precipitation patterns associated with the El Nino/Southern Oscillation. Mon. Wea. Rev., 115, 1606-1626.

Ropelewski, C. F. and Halpert, M. S., 1989: Precipitation patterns associated with the high index phase of the Southern Oscillation. J. Clim., 2, 268-284.

Webster, P. J. and Yang, S., 1992: Monsoon and ENSO: selectively interactive systems. Quart. J. Roy. Meteorol. Soc., 118, 877-926.

WMO, 1992: Simulation of interannual and intraseasonal monsoon variability. WMO/TDNo. $470,185 \mathrm{pp}$.

WMO, 1993: Simulation and prediction of monsoons: Recent results. WMO/TD-No. 546, $73 \mathrm{pp}$. 